\title{
Enhanced Control of Offshore Wind Farms Connected to MTDC Network Using Partially Selective DC Fault Protection
}

\author{
Lei Shi, Grain Philip Adam, IEEE Member, Rui Li and Lie Xu, IEEE Senior Member
}

\begin{abstract}
In recent years, several DC fault clearance schemes have emerged, in which reduced number of fast acting DC circuit breakers (DCCBs) and AC circuit breakers (ACCBs) are used to clear DC faults. In offshore DC grids, such approach entails opening of the ACCBs that connect the wind farms to the offshore HVDC stations which control offshore AC voltages and frequencies, potentially leading to uncontrolled offshore voltage and frequency. Existing studies show that the loss of offshore converter due to blocking or sudden opening of ACCBs can cause significant over-voltage and over-frequency in the offshore AC grid, which could necessitate immediate shutdown of the wind farm. An enhanced control for wind turbine converters (WTCs) of the offshore wind farm is proposed to enable retention of $\mathrm{AC}$ voltage and frequency control when the offshore converter is lost, in which seamless transition of the WTCs between grid following and forming modes is facilitated. The viability of the proposed control is demonstrated in wider context of partially selective DC fault protection in an illustrative meshed DC grid, which includes detailed implementations of DC fault clearance, system restart and power transfer resumption. The presented simulation results confirm the effectiveness of the proposed WTC control in preventing excessive rise of offshore $\mathrm{AC}$ voltage and frequency and facilitating DC fault ride-through using reduced number of DCCBs.

Index Terms-DC fault; DC fault protection; multi-terminal HVDC; offshore wind farm control; partially selective DC fault protection.
\end{abstract}

\section{INTRODUCTION}

To meet Europe's climate goals, 50-100 GW of offshore wind power could be provided from the North and Baltic Seas by 2030 [1]. Among several transmission system technologies, voltage source converter (VSC) based high-voltage DC (HVDC) technology is considered a cost-effective and technical viable solution for connection of long distance offshore wind farms (OWFs) [2-6]. However, the majority of HVDC connected OWFs use point-to-point links. Serval studies and projects concluded that multi-terminal DC (MTDC) network can increase power transmission system reliability by reducing the overall downtimes of "loss of infeed", and lower investment and operation cost [7-9].

DC fault protection is a major technical obstacle that prevents the development of reliable MTDC grids and has drawn significant attention from academia and industry [10-12]. Several protection concepts have been proposed to facilitate fault isolation in offshore MTDC networks.

This project has received funding from the European Union's Horizon 2020 research and innovation program under grant agreement No 691714.
In [13], a DC fault protection method that uses AC circuit breakers (ACCBs) and fast DC dis-connectors to isolate DC fault and facilitates system restoration is proposed. This method sacrifices DC grid continued operation in favor of post-fault operation that prioritizes reduction of the outages and partial system restoration by deliberate separation of healthy parts of the DC from the faulty part. However, it is extremely slow and inadequate for critical power corridors because of the use of slow ACCBs for DC fault clearance.

The work in [14] has analyzed and discussed several recovery sequences of modular multilevel converters (MMCs) and their impacts on overall behaviors of MTDC networks. Also, it has provided extensive guidelines for recovery sequences of grid following and forming converters, covering a range of actions, including converter de-blocking and ACCB reclosing. However, the approaches in $[13,14]$ lead to brief shut down of the whole DC grid following fault inception and take relatively long period to interrupt DC fault currents and to isolate the faulty line.

To minimize power interruption through prevention of total shut down of the DC grid, the uses of different types of DC circuit breakers (DCCBs) are investigated in [15-17] in effort to enable fast and selective fault clearance in MTDC networks. However, the high costs and large footprints of DCCBs and their associated current limiting inductors reduce the viability of offshore DC grids.

A DC fault ride-through method in MTDC grids is investigated in [18], in which a dedicated fault clearance and system restoration sequence are discussed when fault blocking converters such as the full-bridge MMC and high speed DC switches are employed. Although this approach demonstrated in [18] is known to be technically effective and practically attractive to avoid high cost of DCCBs, it does not facilitate continued operation as opening of the DC switches associated with the faulty line necessitates near zero DC current, indicating the need for complete shutdown of the MTDC grid for short period of time.

In addition to the use of DCCBs and DC switches, isolated DC-DC transformer that permits DC zone partitioning as discussed in $[19,20]$ can facilitate rapid containment and isolation of the DC fault branches, while the healthy segments remain operational. Nonetheless, such an approach adds cost and conversion losses. Besides, the impact of HVDC transmission system topologies on multi-terminal DC network

The authors are with the Department of Electronic and Electrical Engineering, University of Strathclyde, Glasgow, G1 1XW UK. 
This paper is a post-print of a paper submitted to and accepted for publication in the IEEE Journal of Emerging and Selected Topics in Power Electronics and is subject to Institution of Electrical and Electronic Engineering Copyright. The copy of record is available at IEEE Xplore Digital Library.

fault has been studied [21, 22] and it concludes that a special care must be taken to design the system and circuit breaker ratings at grounded busbar as it has a higher fault current on the faulty line for the bipolar configuration.

In summary, most of existing works are focusing the MTDC grid dynamics, topologies and protections during DC faults and their main impact on the surrounding AC system. The behaviors for OWF grids during DC faults in the MTDC network still need a detailed investigation. The over-voltage phenomena that arises when the offshore MMC is blocked during DC faults is studied in [23], in which the issues of uncontrolled frequency and harmonic resonance within the offshore AC grids are also highlighted.

Therefore, in effort to address some of the outstanding technical and economic challenges that DC faults present to offshore MTDC grid, this paper proposes an enhanced wind farm control to facilitate realization of partially selective DC fault ride-through and protection, without significant compromise on DC grid continued operation and wind farm AC voltage and frequency regulation, nor excessive cost of DCCBs. The main contributions of this paper are as follows:

- An enhanced passive voltage control for offshore wind turbine converters (WTCs) is proposed to cope with loss of offshore MMC station due to blocking or sudden opening of ACCBs during a DC fault and enable offshore grid restoration. The proposed control strategy utilizes local measurements to initiate WTC fail-safe operation and seamlessly transits between grid following and grid forming modes.

- The value and viability of the proposed WTC control is demonstrated in broader context, particularly, when a partially selective DC fault protection method that uses reduced number of DCCBs is employed to facilitate DC fault isolation and ride-through and system restoration.

The rest of the paper is organized as follows: Section II describes the behaviors of offshore WTCs during DC faults and discusses control requirements for offshore WTCs to enable partially selective DC fault protection in MTDC grids. Section III proposes an enhanced passive voltage control strategy for WTCs that utilizes the offshore AC over-voltage phenomena as an indicator to initiate WTC fail-safe control mode in effort to ride-through DC faults. Section IV introduces the test frameworks for this paper and describes the implementation of the partially selective protection sequence. The effectiveness of the proposed enhanced wind farm control method is confirmed by numerical simulations in Section V. Finally, conclusions are drawn in Section VI.

\section{OFFSHORE WTC BEHAVIORS DURING DC FAULTS AND FUNCTIONAL REQUIREMENTS FOR POST FAULT RECOVERY IN MTDC NETWORKS}

Fig. 1 shows a simplified depiction of the offshore section of a HVDC connected OWF, which consists of a half-bridge (HB) submodule based offshore MMC and three wind turbine clusters represented by aggregated WTCs.

During a DC short circuit fault, the offshore MMC that sets $\mathrm{AC}$ voltage and frequency of the offshore AC grid is blocked and the offshore AC voltage will experience significant reduction which is similar to a severe offshore three-phase AC fault, forcing WTCs to operate at their current limits. The fault current will feed to the DC side through MMC's anti-parallel diodes.

When the main ACCB is opened to isolate the DC fault (assuming DCCBs not used at the offshore MMC terminal), the offshore WTCs will be isolated from the MMC that defines offshore AC voltages and frequency. Such scenario leads to loss of control over the offshore AC frequency and voltage [20]. As the WTCs continue operating in grid following mode, the controllers will saturate to its maximum modulation index of 1 , as demonstrated in Fig. 2 (a). The DC choppers are activated to dissipate the generated wind power, and the DC voltage of the WT increases from 1 to $1.1 \mathrm{pu}\left(1 / 2 V_{d c}=725\right.$ to $\left.797.5 \mathrm{kV}\right)$ as shown in Fig. 2 (b). The saturation of the modulation index to its maximum value of 1 results in overvoltage at the offshore AC network [23-25], as observed in Fig. 2 (b). Similarly, the offshore frequency previously regulated by the offshore MMC will diverge after the blocking of the MMC, potentially leading to circulating power among wind turbine converters and resonance issues as presented in [24]. Such behavior leads to the shutdown of the offshore wind farm to avoid the catastrophic failures.

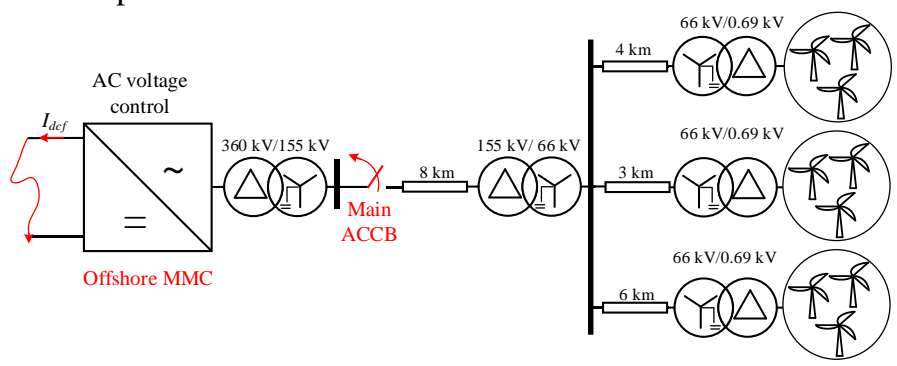

Fig. 1 Aggregated offshore wind farm model.

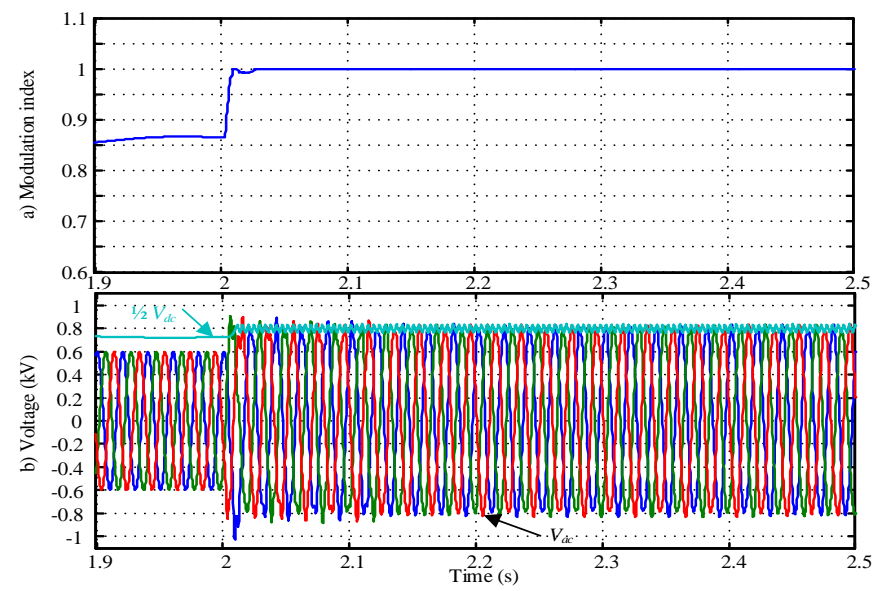

Fig. 2 Overvoltage phenomena with conventional control method when offshore ACCB opens at $t=2 \mathrm{~s}$ : (a) total modulation index, (b) converter side $\mathrm{AC}$ voltages and half of DC voltage.

In a MTDC grid that connects multiple OWFs, continued operation in an effort to retain large proportion of pre-fault power transfer to the consumption centers during a DC fault is critically important. This renders the existing arrangements inadequate. Highly selective protection system in which DCCBs can isolate faulty DC lines in less than $5 \mathrm{~ms}$ without the need for converter blocking provides a viable technical solution for handling DC faults in MTDC grids. However, the high cost of DCCBs has led to quest for low-cost alternatives such as partially selective DC fault protection strategies that use a 
This paper is a post-print of a paper submitted to and accepted for publication in the IEEE Journal of Emerging and Selected Topics in Power Electronics and is subject to Institution of Electrical and Electronic Engineering Copyright. The copy of record is available at IEEE Xplore Digital Library.

combination of reduced number of DCCBs and slow ACCBs to clear DC faults while retaining some of the pre-fault power transfers [26]. Nonetheless, the slow partially selective DC fault protection strategy requires significant modifications to WTC control, particularly, to maintain offshore AC voltage and frequency for extended period of time in the orders of several seconds after the blocking of offshore MMC.

Some of the desirable control requirements of WTCs to facilitate partially selective DC fault ride-through strategies in MTDC grids are:

1) Each WTC autonomously treats AC and DC faults in the same manner by controlling its fault current contribution to the fault. The freewheeling diodes of the blocked offshore MMC can sustain limited fault currents from the WTCs until opening of the main ACCB.

2) WTCs must rely on local measurements for detection of abnormal offshore grid conditions, and initiation of automatic transition from grid following to grid forming control mode to maintain AC voltage and frequency of the isolated offshore $\mathrm{AC}$ grid after opening of the main ACCB.

3) Disintegration of the islanded offshore $\mathrm{AC}$ grid must be prevented to avoid time consuming shutdown and restart of individual WTCs.

4) When the faulty DC line is isolated, WTCs must automatically detect the fault clearance, initiate orderly transition back to the grid following control mode and resume power transfer.

\section{ENHANCED CONTROL OF WIND TURBINE GRID-SIDE CONVERTERS}

To facilitate partially selective DC fault ride-through control in line with the requirements outlined in Section II, a new enhanced WTC control shown in Fig. 3 is proposed. The proposed control method uses a passive $V_{a c}$ controller highlighted in Fig. 3 to facilitate seamless transition of the WTCs between grid following (during normal operation) and grid forming (during MMC blocking) modes based on the local measurements, and fast resumption of power transfer after fault clearance. The enhanced WTC control method shown in Fig. 3 consists of active power or DC voltage $\left(P / V_{d c}\right)$ and reactive power $(Q)$ controllers in the outer loops and passive $V_{a c}$ controller that manipulates the output dynamic limiters of the $P / V_{d c}$ controllers to facilitate smooth transition of WTC control modes. For ease of illustration, four operating modes are considered as follows.

\section{A. Normal operation}

As the set-point of the passive $V_{a c}$ controller is fixed at 1.05 $\mathrm{pu}$, its output will saturate at maximum current $I_{d \max _{-} v}(1.1 \mathrm{pu}$ in this study) during normal operation when the offshore MMC that operates in grid forming mode tightly controls the $\mathrm{AC}$ voltage and frequency in the offshore AC network. As the dynamic current limit $I_{d m a x_{-} v}$ imposed at the output of the $P / V_{d c}$ controller by the passive $V_{a c}$ controller is greater than the nominal $d$-axis current (1 pu in this study), the normal operation of the $P / V_{d c}$ control is not affected. In addition, saturation of the passive $V_{a c}$ controller will force the output of the auxiliary $q$ axis voltage controller in the passive $V_{a c}$ control, which is incorporated into the $Q$ controller to act on $q$-axis, to zero. This allows $Q$ controller to define the entire $q$-axis current order $I_{q}^{*}$.
Also, saturation of the passive $V_{a c}$ controller during the abovementioned scenarios is designed to ensure the output of the PI controller of the phase locked loop (PLL) is unaffected as the dynamic frequency limit $\pm \Delta \omega_{\max }$ is set at the maximum by the proposed $V_{a c}$ controller $\left(\Delta \omega_{\max }=\mathrm{K}_{\mathrm{f}} I_{d \max \_} v\right.$, Fig. 3). Thus, individual WTC follows the PLL detected AC frequency (around $\omega_{0}$ set by the offshore MMC).

\section{B. Fault mode}

This mode represents the period after DC fault inception, in which the main ACCB in Fig. 1 remains closed and offshore grid AC voltage collapses similarly to that typically occurring during offshore symmetrical three-phase AC faults. As a result, the WTC DC choppers will be activated to dissipate excessive active power in WTCs. When the offshore AC voltage $V_{a c}$ becomes lower than the pre-set threshold, e.g. $0.5 \mathrm{pu}$ as illustrated in Fig. 3, the fault current control will be activated to provide maximum reactive current to support offshore AC voltage [27]. Thus, the WTCs will operate at their maximum current limitation with reactive current as priority (denoted as $I_{d \max }=\sqrt{1^{2}-I_{q}^{* 2}}$ in Fig. 3) while the proposed passive $V_{a c}$ controller remains inactive.
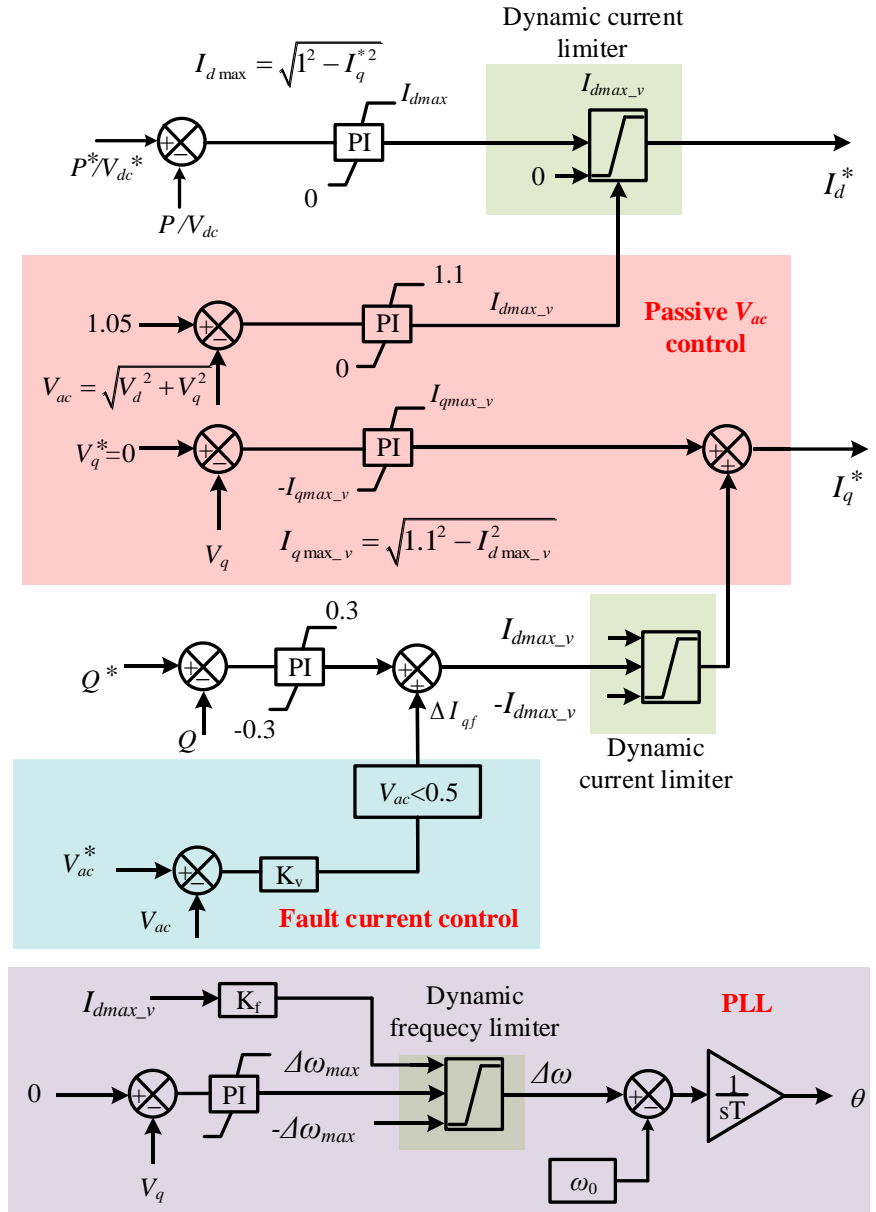

Fig. 3 Proposed control strategy of wind turbine grid-side converters.

\section{Open circuit mode}

When the offshore MMC station that sets the offshore AC voltage and frequency is lost due to opening of the main ACCB, the offshore AC voltage will rise, and frequency will drift as described earlier. The passive $V_{a c}$ controller is thus out of 
This paper is a post-print of a paper submitted to and accepted for publication in the IEEE Journal of Emerging and Selected Topics in Power Electronics and is subject to Institution of Electrical and Electronic Engineering Copyright. The copy of record is available at IEEE Xplore Digital Library.

saturation and its output is reduced from the upper limit of 1.1 pu to a lower value (close to zero) which is substantially less than the output from the $P / V_{d c}$ controller. This forces the $d$-axis current order $I_{d}^{*}$ to follow that from the passive AC voltage controller, and thus $V_{a c}$ is maintained at $1.05 \mathrm{pu}$. As the output of the passive AC voltage controller $I_{d m a x_{-} v}$ will be approaching zero as it limits the $\mathrm{AC}$ voltage at 1.05 pu after its activation, the output of the PLL $\Delta \omega$ will be forced toward zero ( $\Delta \omega=\Delta \omega_{\max }=\mathrm{K}_{\mathrm{f}} I_{d m a x \_} \approx 0$, Fig. 3), thus, allowing loose locking of the individual WTC to nominal pre-fault frequency $\omega_{0}$. The activation of the passive $V_{a c}$ controller also enables the auxiliary $q$-axis voltage controller as its limit is no long set at zero, i.e. $I_{q m a x_{-} v}>0$. The $q$-axis voltage controller aims to force the $q$ axis voltage $V_{q}$ of each WTC to zero to maintain the synchronization of the offshore grid. In this manner, seamless, autonomous and controlled transition of the WTCs between grid following and forming modes based on local measurements is achieved. Thus, compared with the conventional grid following control method [23-25] as in Fig. 2 , the passive AC voltage controller avoids the saturation of the WTC controller so as to maintain the offshore AC voltage as demonstrated in Fig. 4.

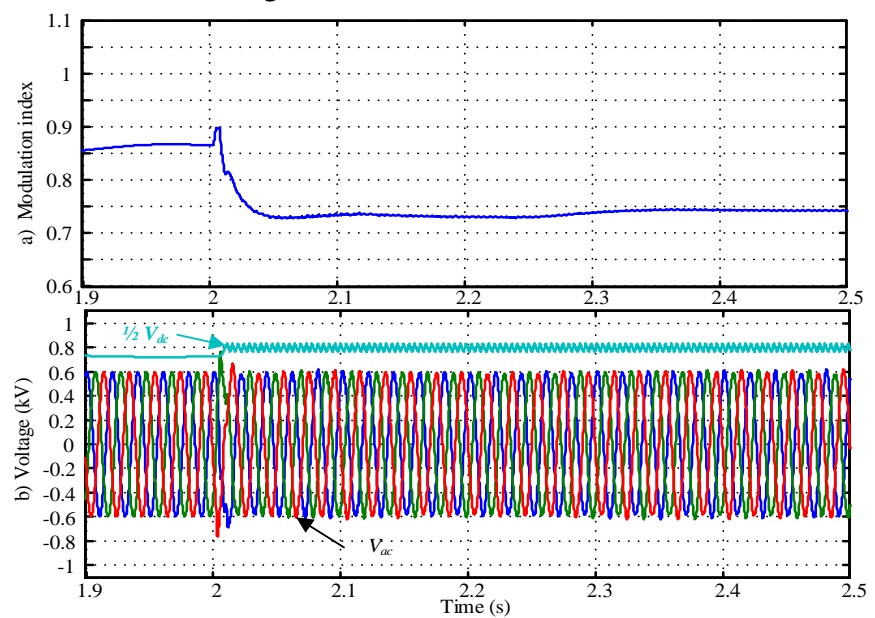

Fig. 4 Waveforms with the proposed control when offshore ACCB opens at $t=2$ s: (a) total modulation index, (b) converter side AC voltages and half of DC voltage.

\section{DC fault recovery}

If the fault is in other part of the MTDC network and after the fault is isolated, the ACCB closes while the WTCs continue controlling the offshore AC network voltage and frequency with the proposed control. The offshore MMC station is thus re-energized by the offshore wind farm. After re-energization, the offshore MMC is activated and operates on DC voltage control mode with PLL activated (Mode $=1$ as illustrated in Fig. $5)$. When the DC voltage of the offshore MMC station is close to that of the DC grid, the offshore MMC can be connected to the DC grid. Then, the offshore MMC station switches back to offshore $\mathrm{AC}$ voltage control mode and regulates the offshore $\mathrm{AC}$ grid voltage at the nominal value (i.e. $1 \mathrm{pu}$ ). This forces the passive $V_{a c}$ controllers of WTCs to saturate again and move back to idle state. The WTCs thus return to grid following mode automatically.
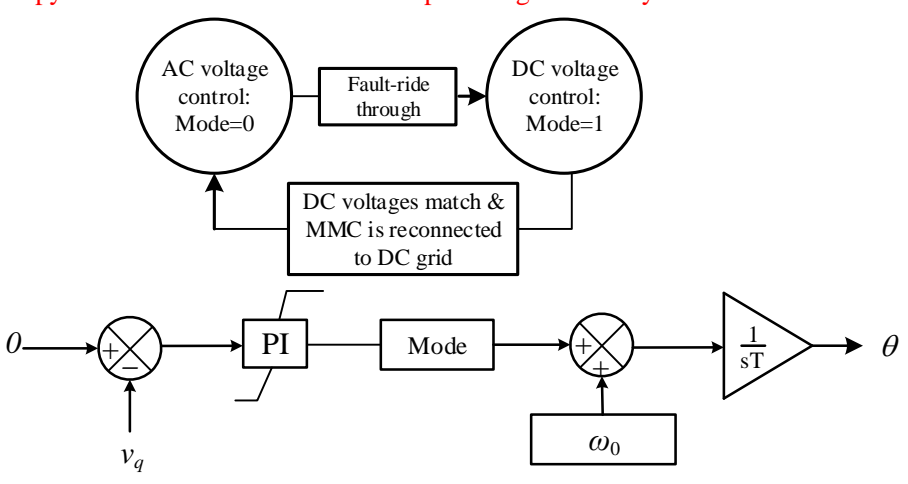

Fig. 5 Criterion of mode switching for the offshore MMC station.

\section{Partially Selective DC Fault Ride-Through}

This section uses an example DC grid shown in Fig. 6 to explain the integration of the proposed WTC control presented in Section III into high-level partially selective DC fault protection for offshore wind farm connected to onshore $\mathrm{AC}$ grids via meshed DC grids. The section describes the illustrative DC grid in Fig. 6, followed by explanation and demonstration of the pivotal role the proposed enhanced WTC control can play in facilitating partially selective DC fault ridethrough of DC connected offshore wind farms.

\section{A. Meshed Four-Terminal DC Network}

All the four HVDC stations of the DC grid in Fig. 6 are modeled as MMCs with $350 \mathrm{HB}$ submodules per arm using an electromagnetic Thevenin equivalent model from the PSCAD library. Each MMC is equipped with the following controllers: DC voltage/active power/AC voltage, AC currents, circulating current suppression, and voltage based vertical and horizontal energy balancing [28, 29]. Table I lists the detailed parameters of the MMC stations. All the $320 \mathrm{kV}$ XLPE HVDC submarine cables shown in Fig. 6 are modelled using a Frequency Dependent Phase Model [18]. The control functions allocated to converter stations are:

- $\quad$ MMC 1 regulates the DC voltage of the DC network at 640 $\mathrm{kV}$, and reactive power exchange at PCC 1 at zero.

- MMC 2 injects $1000 \mathrm{MW}$ into PCC 2 at unity power factor.

- Both MMC 3 and MMC 4 set the AC voltage and frequency at $155 \mathrm{kV}$ and $50 \mathrm{~Hz}$ for the offshore networks of OWF 1 and 2 .

Each of the $1200 \mathrm{MW}$ OWF 1 and 2 shown in Fig. 6 is modelled as three aggregated WTCs with PMSG based Type 4 wind turbines and each WTC is rated at $400 \mathrm{MW}$, as illustrated in Fig. 1. The generator-side converter of the WTC is simplified as a DC current source with constant power control, DC capacitor and DC choppers [24] for fast simulation while the grid-side converter is represented by detailed switching models. The WTCs are connected to the offshore main collection busbar through $66 \mathrm{kV}$ AC cables with different lengths.

\section{B. Proposed Partially Selective DC Fault Ride-Through}

This section describes a partially selective DC fault ridethrough using the four-terminal DC grid shown in Fig. 6 as an example, which aims to reduce investment costs and meet the requirements described in Section II. The cost reduction is achieved by restricting the use of expensive DCCBs only at the onshore converter DC terminals, while the offshore end of each 
This paper is a post-print of a paper submitted to and accepted for publication in the IEEE Journal of Emerging and Selected Topics in Power Electronics and is subject to Institution of Electrical and Electronic Engineering Copyright. The copy of record is available at IEEE Xplore Digital Library.

DC cable is connected to offshore converters via fast DC switches (DCSW) to enable DC fault clearance using ACCBs offshore. Such arrangement avoids the use of the expensive offshore platforms for the installation of bulky DC circuit breakers, which is one of the advantages of the presented partially DC fault protection scheme. Considering the offshore station MMC 4, the overall time sequences including fault isolation and fault recovery, and the WTC control modes are illustrated in Fig. 7 and are detailed as follows.
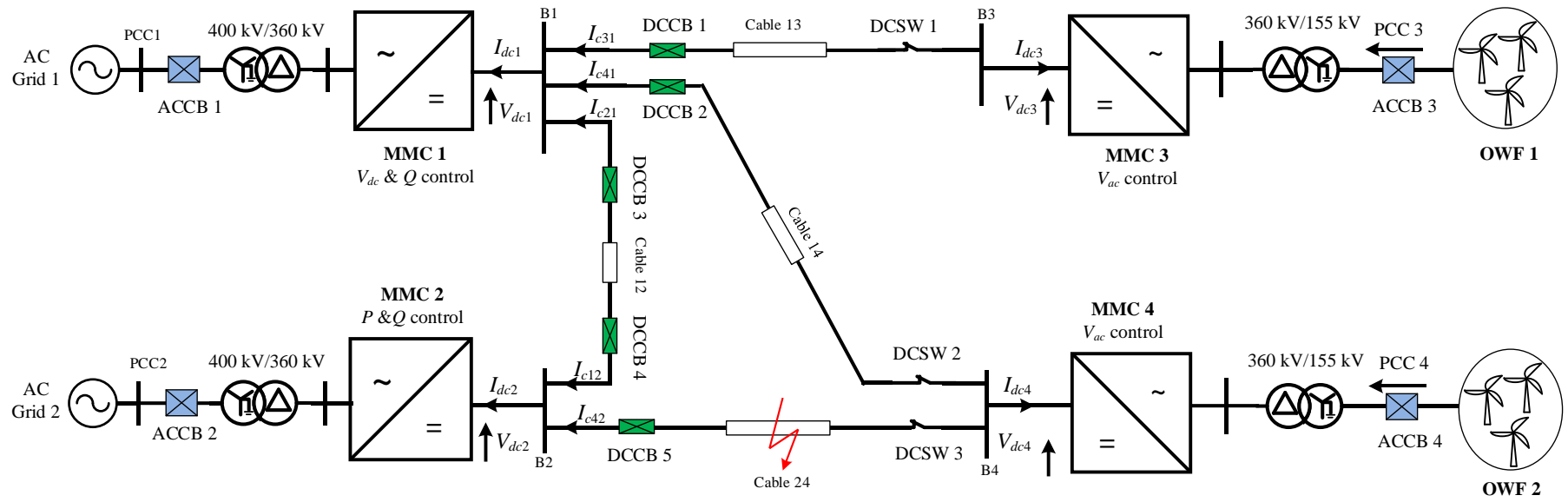

Fig. 6 The meshed four-terminal DC network for offshore wind power transmission.

Table I Nominal Parameters of Tested System

\begin{tabular}{c|c}
\hline Parameter & Nominal value \\
\hline Power & $1200 \mathrm{MW}$ \\
\hline DC voltage & $\pm 320 \mathrm{kV}$ \\
\hline Arm inductance & $42 \mathrm{mH}$ \\
\hline Number of submodules per arm & 350 \\
\hline Submodule capacitor voltage & $1.9 \mathrm{kV}$ \\
\hline Submodule capacitance & $8.8 \mathrm{mF}$ \\
\hline
\end{tabular}

1) Fault isolation

When a DC fault occurs at a particular line in DC grids using partially selective DC fault protection, dedicated DCCBs must be triggered to split the system into healthy and faulty parts. The DC fault detection and localization used in this paper is based on the DC reactor voltage change rate as detailed in [30] to enable a fast and accurate selection for the corresponding DCCBs. Considering the DC fault at Cable 24 connecting DC nodes B2 and B4 in Fig. 6, DCCB 2 and 5 will be opened. In this way, the system will be separated into healthy and faulty parts, with MMC 1, 2 and 3 constituting the healthy section in which the power exchange continues. Thus, the loss-of-infeed from OWFs to onshore AC Grid 1 and 2 is minimized to around $50 \%$.

MMC 4 in the faulty part is blocked upon over-current / under-voltage detection as OWF 2 will contribute limited fault currents to the DC fault through the antiparallel diodes of MMC 4. The fault current contribution from the OWF 2 will continue until ACCB 4 opens to isolate the MMC 4 and the faulty DC side from the offshore AC network. After the ACCB 4 opens, the offshore AC voltage will increase as analyzed in Section II, leading to the activation of the passive $V_{a c}$ controller of WTCs to maintain the offshore $\mathrm{AC}$ voltage and frequency as illustrated in Fig. 7. Operational logics of the ACCBs of the offshore MMCs are designed as follows:

- As shown in Fig. 7, in the first $20 \mathrm{~ms}$ from the fault detection, the ACCB of the affected MMC remains closed so as not to act in case the fault is not at cables directly connected to the offshore MMC.

- After $20 \mathrm{~ms}$ from the fault detection, if the MMC DC voltage remains below $50 \%$ of the rated value, the ACCB is opened. Otherwise, if the MMC DC voltage recovers, the ACCB remains closed.

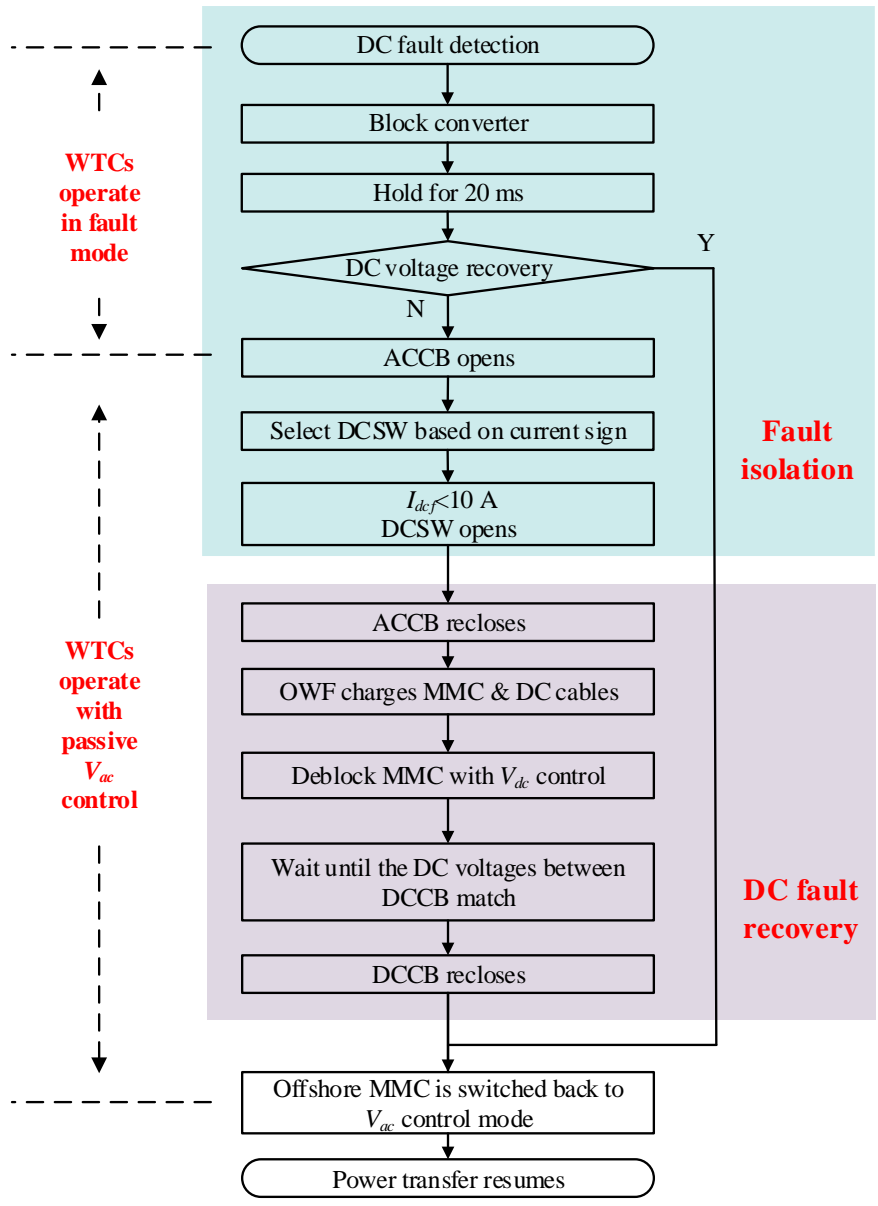

Fig. 7 Sequence of the proposed DC fault protection scheme for the faulty offshore MMC station. 
This paper is a post-print of a paper submitted to and accepted for publication in the IEEE Journal of Emerging and Selected Topics in Power Electronics and is subject to Institution of Electrical and Electronic Engineering Copyright. The copy of record is available at IEEE Xplore Digital Library.

When the installed DC inductors at the DC terminals of the MMCs are unable to prevent the blocking of MMC following remote DC fault due to brief period of over-current, the station will recover quickly as long as its ACCB remains closed and DC voltage recovers as stated in the operational logics described above.

After opening of DCCB 2 and 5, the current in the DCSW 2 will drop to zero, while the fault current contribution from the OWF 2 continues to flow through DCSW 3. The fault is thus detected on the cable connected with DCSW 3, which needs to be opened to isolate the fault. Before opening of the DCSW 3, ACCB 4 must be opened to force the fault current that flows through the DCSW 3 to decay. Once the DC fault current approaches zero (less than $10 \mathrm{~A}$ in this illustration), the DCSW 3 is safely opened to isolate the faulty Cable 24 from MMC 4 .

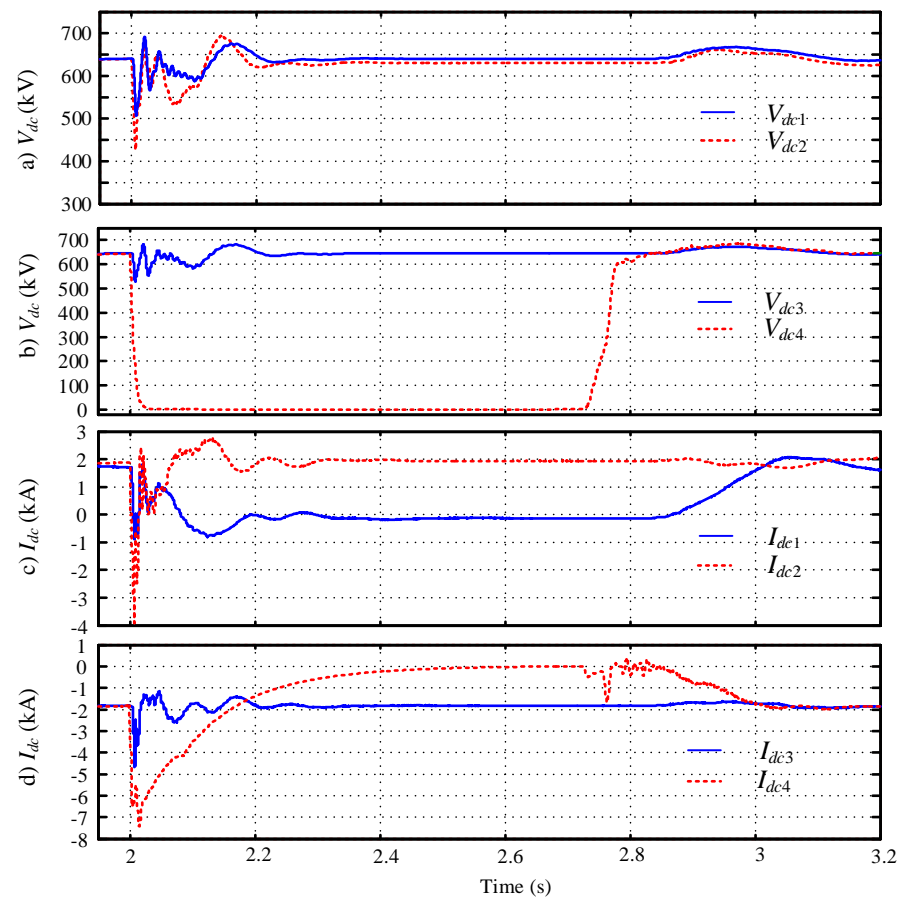

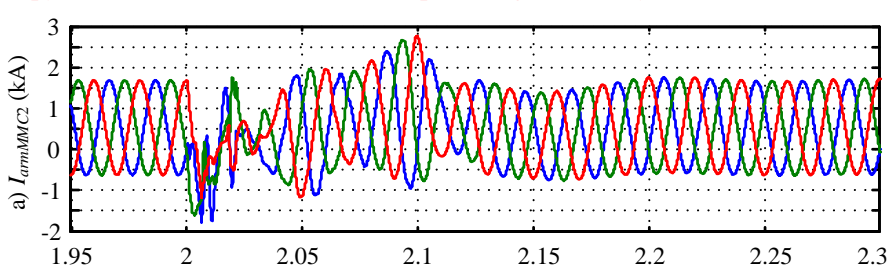

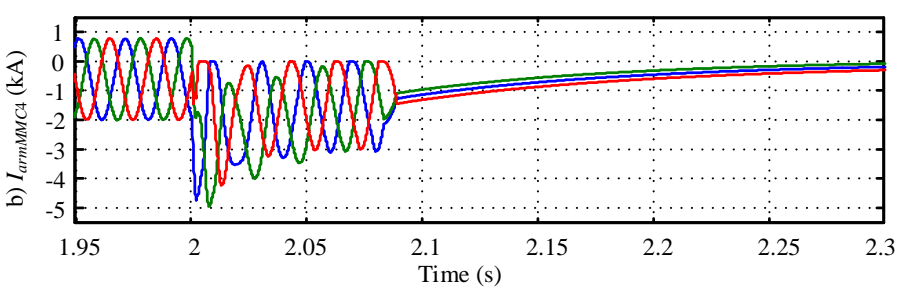

Fig. 8 Upper arm currents of MMC 2 and 4 during the DC fault: (a) onshore MMC 2, (b) offshore MMC 4.

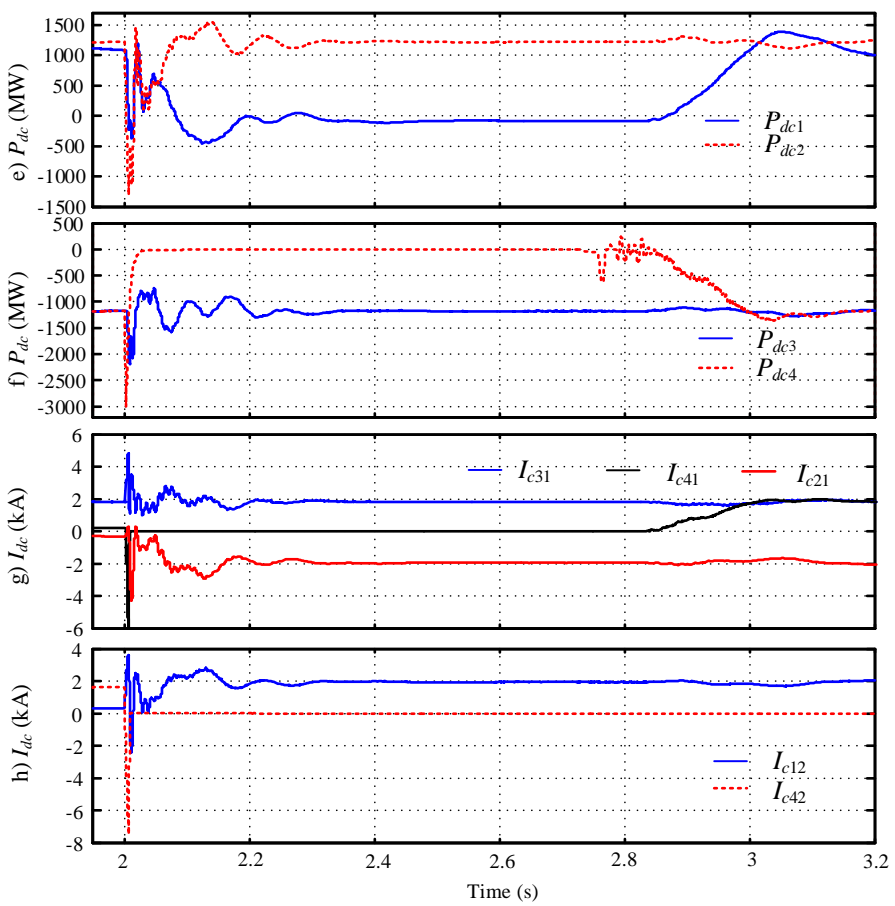

Fig. 9 DC side dynamics during offshore DC fault at Cable 24: (a) onshore DC voltages, (b) offshore DC voltages, (c) onshore DC currents, (d) offshore DC currents, (e) onshore DC power, (f) offshore DC power, (g) DC cable currents flowing to MMC 1, (h) DC cable currents flowing to MMC 2.

\section{2) Fault recovery}

After the isolation of thy faulty cable as described above, MMC 4 and parts of DC network need to be restarted to enable power transmission of OWF 2 through the remaining DC Cable 14. MMC 4 can be re-energized from DC side with the aid of DCCB 2 and DC side pre-charging current limiting resistor. However, the DC side pre-charging resistor needs to be rated at higher voltage to limit possible disturbances to the healthy parts of the DC network with fast communication systems to initiate the restart sequence from onshore when the fault is cleared by the offshore protection system. As the proposed enhanced control allows the WTCs of the OWF 2 to remain operational after opening of the ACCB 4, with the offshore AC network voltage controlled at $1.05 \mathrm{pu}$, the $\mathrm{AC}$ side pre-charging resistor will be rated for relatively low AC voltage compared with DC equivalent. Thus, the WTCs are used to re-energize the offshore
MMC 4 and Cable 14. The detailed restoration sequence is as follows.

- The offshore ACCB 4 recloses and the OWF 2 charges MMC 4 and DC Cable 14 through AC pre-insertion resistors. It should be noted that after the offshore ACCB is closed, the offshore $\mathrm{AC}$ voltage, which is controlled at $1.05 \mathrm{pu}$, is applied at the offshore MMC transformer through pre-insertion resistor (PIR). This may lead to the saturation of the transformer, depending on the residual flux it had earlier, which should be considered in real application. After the DC voltage reaches the rectification value, the PLL of MMC 4 is enabled to track the frequency and angle of the offshore AC grid (now controlled by the WTCs) for synchronization and MMC 4 is then de-blocked and subsequently operated in DC voltage control mode to regulate the DC voltage to the rated value, as illustrated in 
This paper is a post-print of a paper submitted to and accepted for publication in the IEEE Journal of Emerging and Selected Topics in Power Electronics and is subject to Institution of Electrical and Electronic Engineering Copyright. The copy of record is available at IEEE Xplore Digital Library.

Fig. 5. When the DC voltage across the DCCB 2 closes to zero, it is reclosed.

- Following the closure of the DCCB 2, MMC 4 switches back to AC voltage control mode and regulates the offshore AC voltage to the nominal value. This will force the passive $V_{a c}$ controller of the WTCs to saturate, increasing the current limit $I_{\text {dmax }_{v}}$ imposed at the outputs of the active power controllers to the maximum value. Consequently, the WTCs reverse back to power control mode and power transmission of OWF 2 resumes.

It is worth emphasizing that, during the proposed DC fault ride-through, the offshore WTCs automatically change operation mode without any communications as described in Section III.

\section{SimUlation Results}

To assess the effectiveness of the proposed enhanced WTC control that facilitates cost-effective DC fault ride-through in offshore DC grids, a permanent pole-to-pole DC short circuit fault is applied at the middle of Cable 24 at $t=2 \mathrm{~s}$, as illustrated in Fig. 6. The faulty DC line is isolated using a combination of ACCB 4 and DCCB 2 and DCCB 5, with the assistance of MMC 4 as described in Section IV. After isolation of the faulty DC line, the remaining healthy part of the DC grid, which is disconnected from the faulty DC line, is reconnected and reenergized from OWF 2 via the MMC 4 as described in Section IV. The system performances during fault clearance and recovery are addressed in subsections $\mathrm{V}$ A and $\mathrm{B}$, respectively.

\section{A. Fault Clearance}

After DC fault occurrence at $t=2 \mathrm{~s}$, DCCB 2 and 5 open at $t=2.006 \mathrm{~s}$ (after $6 \mathrm{~ms}$ ) to isolate the fault from the healthy part, i.e. MMC 1, 2 and 3 and OWF 1. It is worth underscoring that the onshore stations MMC 1 and 2 are protected by DCCBs plus DC inductors, which help the arm currents of these MMCs to remain below 2 pu ( 1 pu current is $2 \mathrm{kA}$ ) during the fault and thus remain operational without blocking $[12,31]$ as shown in Fig. 8 (a). Observe that the DC voltages of the healthy part experience brief disturbances but quickly recover as shown in Fig. 9 (a) and (b). After system separation into healthy and faulty parts, the majority of the power that OWF 1 injects into the healthy DC network via MMC 3 is transferred to MMC 2 through Cable 13 and 12 as shown in Fig. 9 (e), (f), (g) and (h).

As the offshore MMC 4 uses DC switches with no DC inductors, its DC voltage quickly collapses, as seen in Fig. 10 (a). This leads to the rapid rise of the fault currents. Once the arm current exceeds 2 pu [12, 31], MMC 4 is blocked at 2.0015 $\mathrm{s}$ and the offshore AC network voltage is also collapsed, as shown in Fig. 10 (b), (c) and Fig. 9 (b). With the proposed control, WTCs inject reactive currents to support the offshore AC voltages, which flow through the antiparallel diodes of MMC 4 and feed the fault, as shown in Fig. 10 (b), (d) and (e) and Fig. 9 (b).

Considering $20 \mathrm{~ms}$ delay time and the ACCB operation time, the ACCB 4 opens at $t=2.068 \mathrm{~s}$, leading to isolation of the MMC 4 from the OWF 2. Opening of the ACCB 4 causes the offshore $\mathrm{AC}$ voltage to rise as the WTCs inject currents into the offshore $\mathrm{AC}$ network with no power transmission path. Once the offshore AC voltage increases to $1.05 \mathrm{pu}$ at $t=2.12 \mathrm{~s}$, the passive
$V_{a c}$ controllers incorporated in WTCs are activated to maintain the AC voltage by limiting the active current from the WTCs (i.e. $I_{\text {dmax }_{v}}$ in Fig. 3 is now set around 0 ) as depicted in Fig. 10 (c) and (d). As displayed in Fig. 10 (c), the offshore AC voltage only experiences slight over-voltages for around $23 \mathrm{~ms}$ at the initial stage after the main ACCB opens and the offshore overvoltages are effectively suppressed. At the same time, the dynamic frequency limiter of the PLL loosely locks the offshore frequency at $50 \mathrm{~Hz}$ while the $q$-axis voltage control loop maintains the synchronization for WTCs as in Fig. 10 (f). In this way, both AC voltage and frequency in the offshore network of the OWF 2 are controlled by WTCs.

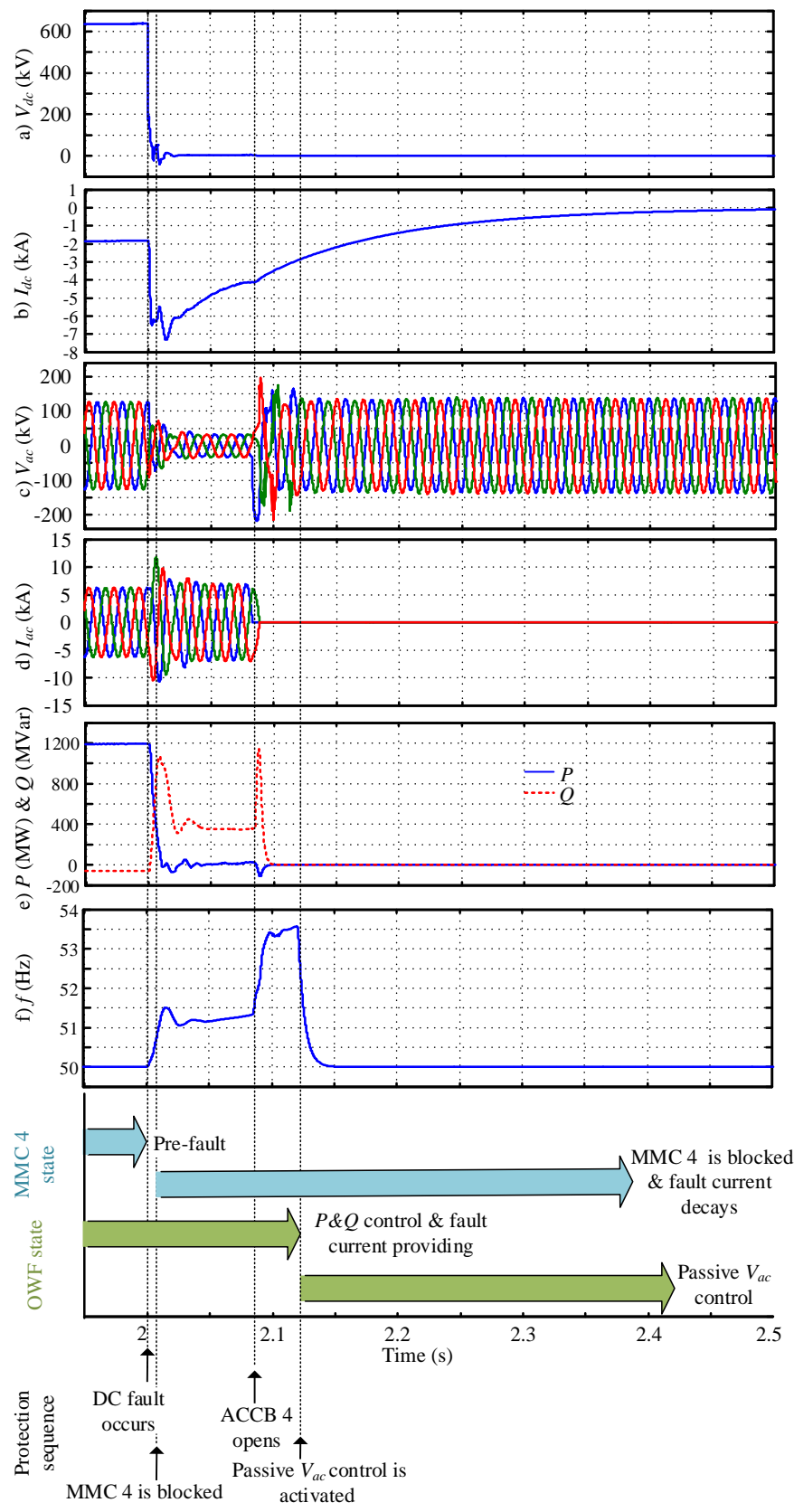

Fig. 10 Waveforms of offshore station MMC 4 and OWF 2 during fault clearance: (a) MMC 4 DC voltage, (b) MMC 4 DC current, (c) WTC AC voltages, (d) WTC AC currents, (e) MMC 4 active and reactive power, (f) WTC frequency. 
This paper is a post-print of a paper submitted to and accepted for publication in the IEEE Journal of Emerging and Selected Topics in Power Electronics and is subject to Institution of Electrical and Electronic Engineering Copyright. The copy of record is available at IEEE Xplore Digital Library.

\section{B. System Recovery}

After isolation of the faulty line from OWF 2 by opening ACCB 4, the fault current contributions from the WTCs stop, forcing the DC current in the faulty DC line to decay to zero as displayed in Fig. 10 (b). The DCSW 3 is opened once its current approaches zero at $t=2.7 \mathrm{~s}$ to isolate the faulty Cable 24 . The offshore MMC 4 is now ready for restart.
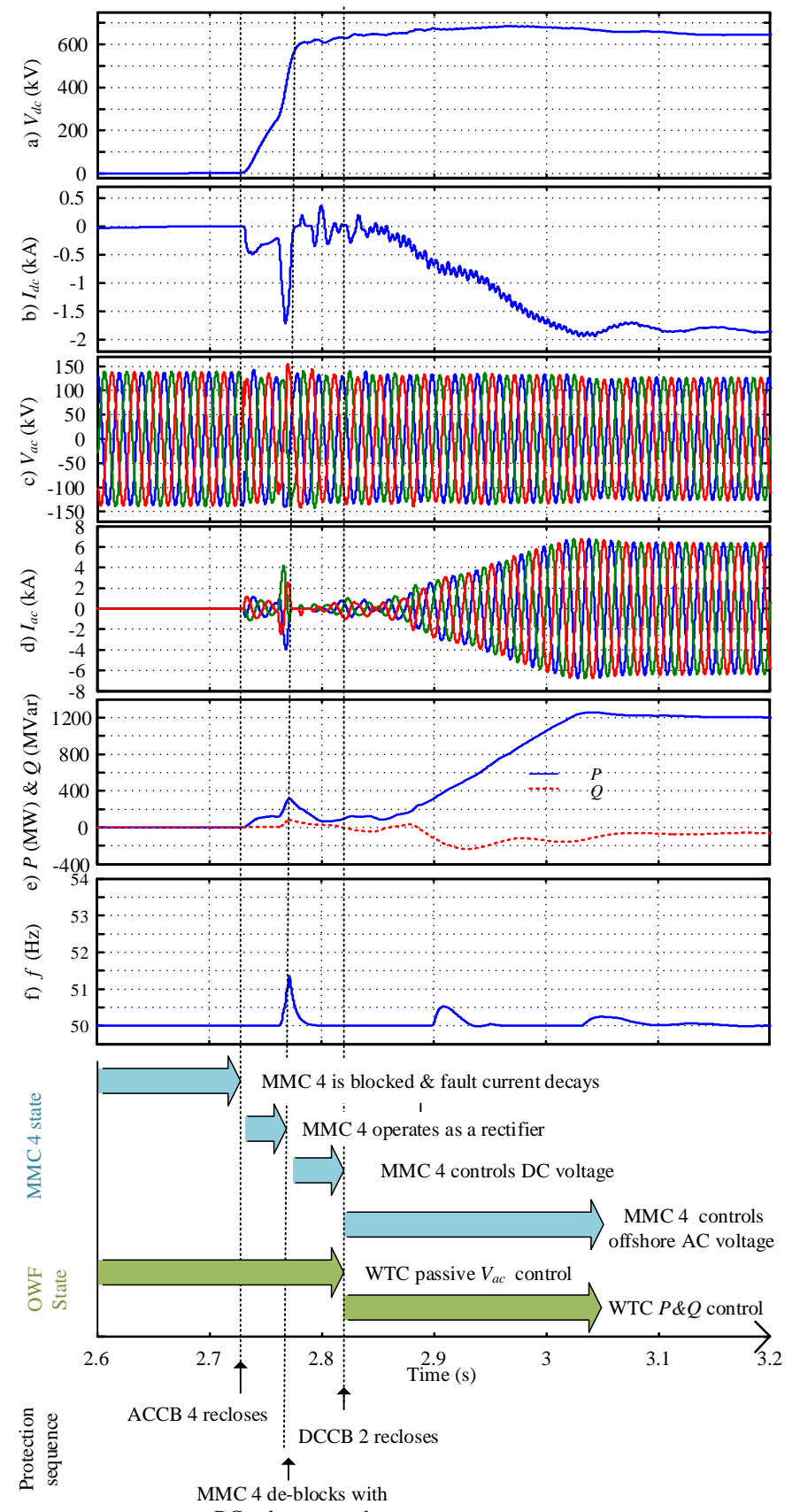

DC voltage control

Fig. 11 Waveforms of offshore station MMC 4 and OWF 2 during system recovery: (a) MMC 4 DC voltage, (b) MMC 4 DC current, (c) WTC AC voltages, (d) WTC AC currents, (e) MMC 4 active and reactive power, (f) WTC frequency.

To avoid DC side disturbance, the DC voltages of MMC 4 and Cable 14 are recovered using OWF 2. Following ACCB 4 reclosing through current limiting PIR at $t=2.73 \mathrm{~s}$, OWF 2 charges the DC link of the blocked MMC 4 and DC Cable 14 through the MMC 4 anti-parallel diodes to $270 \mathrm{kV}$. After bypassing the PIR, the MMC 4 DC link voltage rises to around $580 \mathrm{kV}$ as shown in Fig. 11 (a) and (d). MMC 4 is then deblocked at $t=2.77 \mathrm{~s}$ and operated in DC voltage control mode to boost the DC voltage to $640 \mathrm{kV}$, see Fig. 11 (a). Subsequently, the onshore DCCB 2 is reclosed at $t=2.82 \mathrm{~s}$ when the DC voltages across DCCB 2 match, reconnecting MMC 4 to the DC grid. During the DCCB 2 reclosing process, the DC grid voltages and currents do not exhibit large disturbances as shown in Fig. 11 (a) and (b). MMC 4 subsequently switches back to grid forming mode in which the offshore AC voltage and frequency are restored to $1 \mathrm{pu}$ and $50 \mathrm{~Hz}$, respectively. At this stage, MMC 4 takes control of the AC voltage and frequency, and WTCs of the OWF2 will transit back from passive $V_{a c}$ control to power control mode as the active current upper limit $I_{\text {dmax }_{-} v}$ imposed by the passive AC voltage controller is restored to the maximum value of $1 \mathrm{pu}$.

In summary, simulation results reveal the following:

- The offshore AC current and voltage remain well regulated without showing significant overshoots during the DC fault and DC grid restoration;

- During the fault recovery process, the DC grid remains stable and integration of the proposed control into costeffective partially selective DC fault ride-through method has no adverse impact on the DC grid during extended fault clearance period and reconnection of MMC 4;

- The total system recovery time that the proposed DC fault ride-through scheme offers in this illustration is $1.04 \mathrm{~s}$, and it is dominated by the fault current decay time, which depends on the resistance and inductance of the fault current path.

\section{CONCLUSION}

This paper has proposed an enhanced WTC control method that facilitates partially selective DC fault clearance and ridethrough using reduced number of fast acting DC circuit breakers. To avoid the collapse of offshore AC voltage due to sudden loss of offshore MMCs, the proposed passive AC voltage control of wind turbine converters detects the abnormal condition based on local measurements and seamlessly transits between grid following and forming modes. The offshore grid voltage is thus maintained stable during faults and the offshore restoration after fault clearance is enabled by the proposed control with reduced number of DCCBs. Detailed simulation studies reveal that the proposed WTC control facilitates clearance of DC fault in multi-terminal offshore DC grid, while significant proportion of pre-fault power transfer is retained. Adverse impacts of loss of control over the AC voltage and frequency in the offshore AC network are avoided and orderly DC fault clearance and system recovery are enabled.

\section{REFERENCE}

A. Nghiem and I. Pineda, "Wind energy in Europe: Scenarios for 2030," presented at the in Proc. Wind Europe, Brussels, Belgium, 2017.

R. Blasco-Gimenez, S. A.-. Villalba, J. RodríguezD'Derlée, F. Morant, and S. Bernal-Perez, "Distributed Voltage and Frequency Control of Offshore Wind Farms Connected With a Diode-Based HVdc Link," 
This paper is a post-print of a paper submitted to and accepted for publication in the IEEE Journal of Emerging and Selected Topics in Power Electronics and is subject to Institution of Electrical and Electronic Engineering Copyright. The copy of record is available at IEEE Xplore Digital Library.

IEEE Transactions on Power Electronics, vol. 25, pp. 3095-3105, 2010.

[3] R. Blasco-Gimenez, S. Anó-Villalba, J. RodriguezD'Derlée, S. Bernal-Perez, and F. Morant, "DiodeBased HVdc Link for the Connection of Large Offshore Wind Farms," IEEE Transactions on Energy Conversion, vol. 26, pp. 615-626, 2011.

[4] S. Bernal-Perez, S. Ano-Villalba, R. Blasco-Gimenez, and J. Rodriguez-D'Derlee, "Efficiency and Fault Ride-Through Performance of a Diode-Rectifier- and VSC-Inverter-Based HVDC Link for Offshore Wind Farms," IEEE Transactions on Industrial Electronics, vol. 60, pp. 2401-2409, 2013.

[5] R. Li, L. Yu, and L. Xu, "Offshore AC Fault Protection of Diode Rectifier Unit-Based HVdc System for Wind Energy Transmission," IEEE Transactions on Industrial Electronics, vol. 66, pp. 5289-5299, 2019.

[6] P. Bresesti, W. L. Kling, R. L. Hendriks, and R. Vailati, "HVDC Connection of Offshore Wind Farms to the Transmission System," IEEE Transactions on Energy Conversion, vol. 22, pp. 37-43, 2007.

[7] G. Chaffey and T. C. Green, "Low speed protection methodology for a symmetrical monopolar HVDC network," in 13th IET International Conference on AC and DC Power Transmission (ACDC 2017), 2017, pp. $1-6$.

[8] A. Raza, X. Dianguo, S. Xunwen, L. Weixing, and B. W. Williams, "A Novel Multiterminal VSC-HVdc Transmission Topology for Offshore Wind Farms," IEEE Transactions on Industry Applications, vol. 53, pp. 1316-1325, 2017.

[9] L. Xu and L. Yao, "DC voltage control and power dispatch of a multi-terminal HVDC system for integrating large offshore wind farms," IET Renewable Power Generation, vol. 5, pp. 223-233, 2011.

[10] R. Adapa, "High-Wire Act: HVdc Technology: The State of the Art," IEEE Power and Energy Magazine, vol. 10, pp. 18-29, 2012.

[11] N. A. Belda, C. A. Plet, and R. P. P. Smeets, "Analysis of Faults in Multiterminal HVDC Grid for Definition of Test Requirements of HVDC Circuit Breakers," IEEE Transactions on Power Delivery, vol. 33, pp. 403-411, 2018.

[12] R. Li and L. Xu, "Review of DC fault protection for HVDC grids," Wiley Interdisciplinary Reviews: Energy and Environment, vol. 7, pp. e278-n/a, 2018.

[13] R. Dantas, J. Liang, C. E. Ugalde-Loo, A. Adamczyk, C. Barker, and R. Whitehouse, "Progressive Fault Isolation and Grid Restoration Strategy for MTDC Networks," IEEE Transactions on Power Delivery, vol. 33, pp. 909-918, 2018.

[14] P. Wang, X.-P. Zhang, P. F. Coventry, R. Zhang, and $\mathrm{Z}$. $\mathrm{Li}$, "Control and protection sequence for recovery and reconfiguration of an offshore integrated MMC multi-terminal HVDC system under DC faults," International Journal of Electrical Power \& Energy Systems, vol. 86, pp. 81-92, 2017/03/01/ 2017.

[15] X. Han, W. Sima, M. Yang, L. Li, T. Yuan, and Y. Si, "Transient Characteristics Under Ground and Short-
Circuit Faults in a +-500 MMC-Based HVDC System With Hybrid DC Circuit Breakers," IEEE Transactions on Power Delivery, vol. 33, pp. 13781387, 2018

[16] W. Sanusi, M. A. Hosani, and M. S. E. Moursi, "A Novel DC Fault Ride-Through Scheme for MTDC Networks Connecting Large-Scale Wind Parks," IEEE Transactions on Sustainable Energy, vol. 8, pp. 10861095, 2017

[17] M. A. Parker, D. Holliday, and S. J. Finney, "DC protection for a multi-terminal HVDC network including offshore wind power, featuring a reduced DC circuit breaker count," The Journal of Engineering, vol. 2019, pp. 4511-4515, 2019.

[18] P. Ruffing, N. Collath, C. Brantl, and A. Schnettler, "DC Fault Control and High-Speed Switch Design for an HVDC Network Protection Based on FaultBlocking Converters," IEEE Transactions on Power Delivery, vol. 34, pp. 397-406, 2019.

[19] M. H. Rahman, L. Xu, and Y. Liangzhong, "DC fault protection strategy considering DC network partition," in 2016 IEEE Power and Energy Society General Meeting (PESGM), 2016, pp. 1-5.

[20] Y. Zhao, L. Shi, L. Yao, Z. Xu, and Y. Ni, "Zone partitioning protection strategy for DC systems incorporating offshore wind farm," IET Renewable Power Generation, vol. 11, pp. 1509-1516, 2017.

[21] E. Kontos, R. T. Pinto, S. Rodrigues, and P. Bauer, "Impact of HVDC Transmission System Topology on Multiterminal DC Network Faults," IEEE Transactions on Power Delivery, vol. 30, pp. 844-852, 2015.

[22] P. R. C. BRANTL*, P. TÜNNERHOFF, R. PUFFER, "Impact of the HVDC system configuration on DC line protection," in Proc. CIGR 'ESymp, Aalborg, Denmark, 2019.

[23] I. Erlich, B. Paz, M. K. Zadeh, S. Vogt, C. Buchhagen, C. Rauscher, et al., "Overvoltage phenomena in offshore wind farms following blocking of the HVDC converter," in 2016 IEEE Power and Energy Society General Meeting (PESGM), 2016, pp. 1-5.

[24] I. Erlich, A. Korai, T. Neumann, M. K. Zadeh, S. Vogt, C. Buchhagen, et al., "New Control of Wind Turbines Ensuring Stable and Secure Operation Following Islanding of Wind Farms," IEEE Transactions on Energy Conversion, vol. 32, pp. 1263-1271, 2017.

[25] T. Neumann, I. Erlich, B. Paz, A. Korai, M. K. Zadeh, S. Vogt, et al., "Novel direct voltage control by wind turbines," in 2016 IEEE Power and Energy Society General Meeting (PESGM), 2016, pp. 1-5.

[26] M. H. Rahman, L. Xu, and L. Yao, "Protection of Large Partitioned MTDC Networks Using DC-DC Converters and Circuit Breakers," Protection and Control of Modern Power Systems, vol. 1, p. 19, 2016.

[27] Y. Jing, R. Li, L. Xu, and Y. Wang, "Enhanced AC voltage and frequency control on offshore MMC station for wind farm," The Journal of Engineering, vol. 2017, pp. 1264-1268, 2017.

[28] D. Guo, M. H. Rahman, G. Adam, L. Xu, A. Emhemed, G. M. Burt, et al., "Detailed quantitative 
This paper is a post-print of a paper submitted to and accepted for publication in the IEEE Journal of Emerging and Selected Topics in Power Electronics and is subject to Institution of Electrical and Electronic Engineering Copyright. The copy of record is available at IEEE Xplore Digital Library.

comparison of half-bridge modular multilevel converter modelling methods," in The 14th IET International Conference on $A C$ and DC Power Transmission (ACDC 2018), 28-30 June 2018.

[29] L. Shi, G. P. Adam, R. Li, and L. Xu, "Control of Offshore MMC during Asymmetric Offshore AC Faults for Wind Power Transmission," IEEE Journal of Emerging and Selected Topics in Power Electronics, pp. 1-1, 2019.

[30] R. Li, L. Xu, and L. Yao, "DC Fault Detection and Location in Meshed Multiterminal HVDC Systems Based on DC Reactor Voltage Change Rate," IEEE Transactions on Power Delivery, vol. 32, pp. 1516$1526,2017$.

[31] X. Li, Q. Song, W. Liu, H. Rao, S. Xu, and L. Li, "Protection of Nonpermanent Faults on DC Overhead Lines in MMC-Based HVDC Systems," IEEE Transactions on Power Delivery, vol. 28, pp. 483-490, 2013.

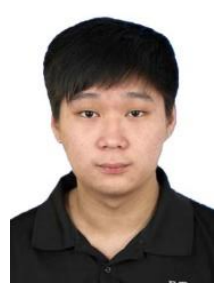

Lei Shi received the B.Sc. degree with first class honour from University of Strathclyde, Glasgow, U.K., in 2016. He is currently pursuing the Ph.D. degree in Electronic and Electrical Engineering.

His current research interests include HVDC transmission systems and offshore windfarm systems.

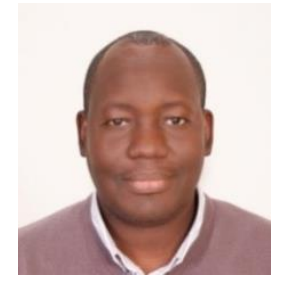

Grain P. Adam (M'12) received the B.Sc. and M.Sc. degrees (Hons.) from Sudan University for Science and Technology, in 1998 and 2002 respectively; and a PhD in Power Electronics from University of Strathclyde in 2007.

$\mathrm{He}$ has been a researcher with University of Strathclyde in Glasgow, UK, since 2008. His research interests are fault tolerant voltage source converters for HVDC applications; modelling and control of HVDC transmission systems and multi-terminal HVDC networks; voltage source converter based FACTS devices; and grid integration issues of renewable energies.

Dr. Adam has authored and co-authored several technical reports, and over 100 journal and conference articles. Dr. Adam has published two books in applications of power electronics in power systems and renewable energy. $\mathrm{He}$ is an active contributor to the reviewing process for several IEEE and IET Transactions, Journals and conferences, and a member of IEEE. He is an Associate Editor of the IEEE Journal of Emerging and Selected Topics in Power Electronics.

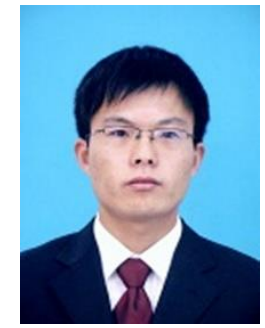

Rui Li received the M.S. and Ph.D degrees in electrical engineering from Harbin Institute of Technology, Harbin, China, in 2008 and 2013, respectively. He is a researcher with University of Strathclyde in Glasgow, UK, since 2013.

His research interests include HVDC transmision systems, grid integration of renewable power, power electronic converters, and energy conversion.

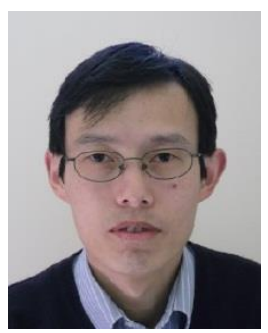

Lie Xu (M'03-SM'06) received the B.Sc. degree in Mechatronics from Zhejiang University, Hangzhou, China, in 1993, and the Ph.D. degree in Electrical Engineering from the University of Sheffield, Sheffield, UK, in 2000.

He is currently a Professor at the Department of Electronic \& Electrical Engineering, University of Strathclyde, Glasgow, UK. He previously worked in Queen's University of Belfast and ALSTOM T\&D, Stafford, UK. His current research interests include power electronics, wind energy generation and grid integration, and application of power electronics to power systems. He is an Editor of IEEE Transactions on Power Delivery and IEEE Transactions on Energy Conversion. 